\title{
Premedication with oral paracetamol for reduction of propofol injection pain: a randomized placebo-controlled trial
}

\author{
Sasikaan Nimmaanrat ${ }^{*}$ (D), Manasanun Jongjidpranitarn, Sumidtra Prathep and Maliwan Oofuvong
}

\begin{abstract}
Background: To compare the effect of premedication with 2 different doses of oral paracetamol to prevent pain at propofol intravenous injection.

Methods: We conducted a double-blind randomized controlled trial in which patients scheduled for induction of general anesthesia with intravenous propofol received either a placebo, $500 \mathrm{mg}$ or $1000 \mathrm{mg}$ of oral paracetamol (P500 and P1000, respectively) $1 \mathrm{~h}$ prior to induction. Two $\mathrm{mg} / \mathrm{kg}$ of propofol was injected at a rate of $600 \mathrm{ml} / \mathrm{hr}$. After $1 / 4$ of the full dose had been injected, the syringe pump was paused, and patients were asked to rate pain at the injection site using a verbal numerical rating score (VNRS) from 0 to 10.

Results: Three hundred and twenty-four patients were included. Pain intensity was lower in both P500 and P1000 groups (median VNRS [interquartile range] $=2[0-3]$ and 4 [2-5], respectively) than in the placebo group (8 [7-10]; $P<0.001)^{*}$. The rate of pain was lower in the P1000 group (70.4\%) than in both the P500 and the placebo group (86.1 and $99.1 \%$, respectively; $P<0.001)^{*}$. The respective rates of mild (VNRS $1-3$ ), moderate (VNRS 4-6) and severe pain (VNRS 7-10) were 47.2, 23.2 and 0\% in the P1000 group, 28.7, 50 and 7.4\% in the P500 group, and 0, 22.2 and $76.9 \%$ in the placebo group ( $P<0.001^{*}$ for between group comparisons). Tolerance was similar in the 3 groups.

Conclusions: A premedication with oral paracetamol can dose-dependently reduce pain at propofol intravenous injection. To avoid this common uncomfortable concern for the patients, this well-tolerated, available and cheap treatment appears as an option to be implemented in the current practice.
\end{abstract}

Trial registration: TCTR20150224002. Prospectively registered on 24 February 2015.

Keywords: Paracetamol, Propofol, Pain, Injection pain

\section{Background}

Propofol (di-isopropylphenol) is the most frequently used agent for the induction of general anesthesia because of its rapid onset and short duration of action. However, pain from the injection is a common problem [1]. The incidence of injection pain has been shown to vary between 28 and $90 \%$ which might be severe $[2,3]$ and the data from Songklanagarind Hospital found the high incidence of pain as $83 \%$.

Pain upon injection of some anesthetic agents are thought to be a direct irritant effect by the non-physiological osmolality or $\mathrm{pH}$ of their preparations

\footnotetext{
* Correspondence: snimmaanrat@yahoo.com.au

Department of Anesthesiology, Faculty of Medicine, Prince of Songkla University, Hatyai, Songkhla 90110, Thailand
}

[4]. Nonetheless, propofol is nearly isotonic, nonhyperosmolar and has a pH from 6 to 8.5. Hence, this concept cannot explain for the pain produced by the injection of propofol [1]. Propofol injection pain may be caused by an effect via the kinin cascade [5]. In addition, many factors seem to contribute to the incidence of injection pain including site [6] and speed of injection [7], size of vein $[7,8]$, rate of intravenous fluid infusion [9], concentration of propofol in the aqueous phase [4] as well as blood buffering effects [10].

A number of approaches have been proposed to lessen the injection pain such as injection of propofol at an antecubital fossa, fast injection [7] and pretreatment with lidocaine [11], opioids [12], or non-steroidal anti-inflammatory drugs (NSAIDs) [13]. The effective

(c) The Author(s). 2019 Open Access This article is distributed under the terms of the Creative Commons Attribution 4.0 International License (http://creativecommons.org/licenses/by/4.0/), which permits unrestricted use, distribution, and 
technique is a combination of lidocaine pretreatment together with venous occlusion (a modified Bier's block) [3]. However, this inflated arm tourniquet technique is quite difficult. From a systematic review and meta-analysis, the most 2 effective procedures to decrease propofol injection pain are injecting through an antecubital vein and pretreatment with lidocaine together with venous occlusion when a hand vein is used [14].

Canbay et al. [15] showed that intravenous acetaminophen (paracetamol) could diminish injection pain. The incidence of pain was significantly reduced to $22 \%$ as compared to a control group but less than lidocaine. Borazan et al. [16] compared the effect of injection of different paracetamol doses with lidocaine. They found that paracetamol $2 \mathrm{mg} / \mathrm{kg}$ administered intravenously 1 min before propofol was more effective than paraceta$\mathrm{mol} 1 \mathrm{mg} / \mathrm{kg}$ and lidocaine in reducing propofol injection pain. The issue of pain at propofol injection pain should be addressed and managed accordingly. We hypothesized that oral paracetamol can reduce the severity of propofol injection pain. Our primary endpoint was pain intensity measured by verbal numerical rating score upon propofol injection. We used oral form of paracetamol because it is easier to administer and much cheaper in comparison to intravenous injection.

Additionally, Seymour et al. [17] demonstrated that a 1000-mg dose was more effective than $500 \mathrm{mg}$ in reducing postoperative pain after third molar surgery. In regard to this study, we aimed to compare the efficacy of paracetamol $500 \mathrm{mg}$ versus $1000 \mathrm{mg}$ for reduction of propofol injection pain.

\section{Methods}

This study was a double-blinded randomized controlled trial (RCT). It was approved by the Faculty of Medicine, Prince of Songkla University Ethics Committee and registered with Thai Clinical Trial Registry (TCTR20150224002: prospectively registered on February 24, 2015). The principal investigator was Dr. Nimmaanrat. The data were collected from June 2015 until February 2016 at Songklanagarind Hospital (Faculty of Medicine, Prince of Songkla University). The authors prepared this trial report in accordance to the Consolidated Standards of Reporting Trials (CONSORT) guidelines. The full protocol is accessible on request.

We recruited 324 patients with the American Society Anesthesiologists (ASA) physical status I-III of who were aged between 18 and 65, scheduled for elective surgeries under general anesthesia, and having an intravenous catheter number 20G at a hand dorsum.

Exclusion criteria included weight less than $50 \mathrm{~kg}$, chronic pain, hypertension, cardiovascular disease or cerebrovascular disease, difficulty in communicating, cirrhosis or abnormal liver function test result (aspartate transaminese (AST), alanine transaminase (ALT) $\geq 2$ times of normal range), renal failure or creatinine clearance $(\mathrm{CrCl}) \leq 10 \mathrm{umol} / \mathrm{L}$, paracetamol and/or propofol allergy. Exclusion criteria also included patients who were not using propofol for an induction, using an intravenous catheter that was not on a hand dorsum, or whereas the size of the catheter was not 20G and had to have a rapid sequence induction.

After obtaining a written informed consent, a randomization was performed by using a block of 6 method. The drugs were prepared by one of the investigators (MJ), with both the patient and an independent assessor (anesthesiologist in-charge) blinded. The groups $\mathrm{Pb}, \mathrm{P} 500$ and $\mathrm{P} 1000$, patients were premedicated with oral placebo, 500 or $1000 \mathrm{mg}$ of paracetamol, respectively $1 \mathrm{~h}$ prior to transferal to the operating room. Each patient received either 2 tablets of placeco (Pb group), 1 tablet of placebo and 1 tablet of paracetamol $500 \mathrm{mg}$ (P500), or 2 tablets of paracetamol $500 \mathrm{mg}$ (P1000). Both placebo and paracetamol were identical in shape, size, color and weight. None of them received any other analgesic or sedative drug. A 20G intravenous catheter was inserted into a superficial vein on the hand dorsum and intravenous fluid at a rate of $80 \mathrm{ml} / \mathrm{hr}$. was infused into each patient.

After preoxygenation, an emulsion of $1 \%$ propofol in a mixture of long-chain and medium-chain triglycerides (Lipuro ${ }^{\circ}$, B Braun) $2 \mathrm{mg} / \mathrm{kg}$ (for obese patients, dose was calculated by using lean body weight) was intravenously administered into each patient with a syringe pump at a rate of $600 \mathrm{ml} / \mathrm{hr}$. $(10 \mathrm{ml} / \mathrm{min})$. After $1 / 4$ of the calculated dose of propofol had been delivered, the infusion pump was temporarily paused and the patient was asked to rate his/her pain at the injection site using an 11-point verbal numerical rating score (VNRS) when 0 is not pain and 10 is the worst pain imaginable. None of them was heavily anesthetized and unable to give the VNRS. The residual dose of propofol was then given, followed by opioids and neuromuscular blocking agent as per usual.

In the operating room and postanesthesia care unit, each patient was carefully evaluated for paracetamol's side effects including rash, swelling, flushing, hypotension and tachycardia.

Statistical analysis was performed by using $\mathrm{R}$ software 2.14.1. Continuous variables were analyzed by ANOVA F- test or Kruskal-Wallis test. Categorical variables were analyzed by ANOVA F-test, Fisher's exact test or Chi-square test. Post-hoc analysis was carried out by using a Bonferroni correction. $P$ value less than 0.05 was considered as statistical significant. Continuous variables were presented as median and interquartile range (IQR) or mean and standard deviation (SD). Categorical variables were presented as number of patients and percentages. The power of this study was 0.9 . 
For sample size calculation, we collected pain intensity by using the 11-point verbal numerical rating score (VNRS) in 30 patients who received propofol for an induction, without having paracetamol for premedication. The mean VNRS in this group of patients was 5.7. Anticipating that patients premedicated with paracetamol would have $25 \%$ less pain (VNRS of 4.2 ), a number of patients per each group was calculated to be 96 . With $10 \%$ drop out, the definite number of patients per each group was 108 .

\section{Results}

A total of 834 patients were assessed for eligibility from June 2015 to February 2016. Five hundred and ten patients were excluded and 324 patients were randomly allocated to each group. Each group equally had 108 patients. All participants were completely analyzed. (Fig. 1) There were no differences between the groups regarding gender, age, weight, height, body mass index (BMI), ASA physical classification and interval between ingestion of paracetamol and injection of propofol. (Table 1).

In all cases, it was possible to achieve a clear response from the patients before they became anesthetized. The overall incidence of pain during propofol injection among the 3 groups is shown in Fig. 2. The incidence of pain was less in the P1000 group (70.4\%) compared with the P500 $(86.1 \%)$ and the Pb groups $(99.1 \%)(P<0.001)$. The incidences of pain by categories of intensity (mild/ moderate/severe) were lower in the P1000 group in comparison to those in the $\mathrm{P} 500$ and the $\mathrm{Pb}$ groups $(P<0.001)$. (Table 2).

The median pain score showed a significant reduction in the P1000 group compared with the P500, and the $\mathrm{Pb}$ groups. Those were $2(0-3), 4(2-5)$, and $8(7-10)$, respectively $(P<0.001)$. (Fig. 3$)$.

There was no incidence of complications such as; rashes or edema of the tissue in each group at the recovery room.

\section{Discussion}

In this study, we found that an oral paracetamol was effective in decreasing the incidence and severity of propofol injection pain when compared with a placebo. Premedication with $1000 \mathrm{mg}$ of paracetamol was also more effective in reducing propofol injection pain than $500 \mathrm{mg}$.

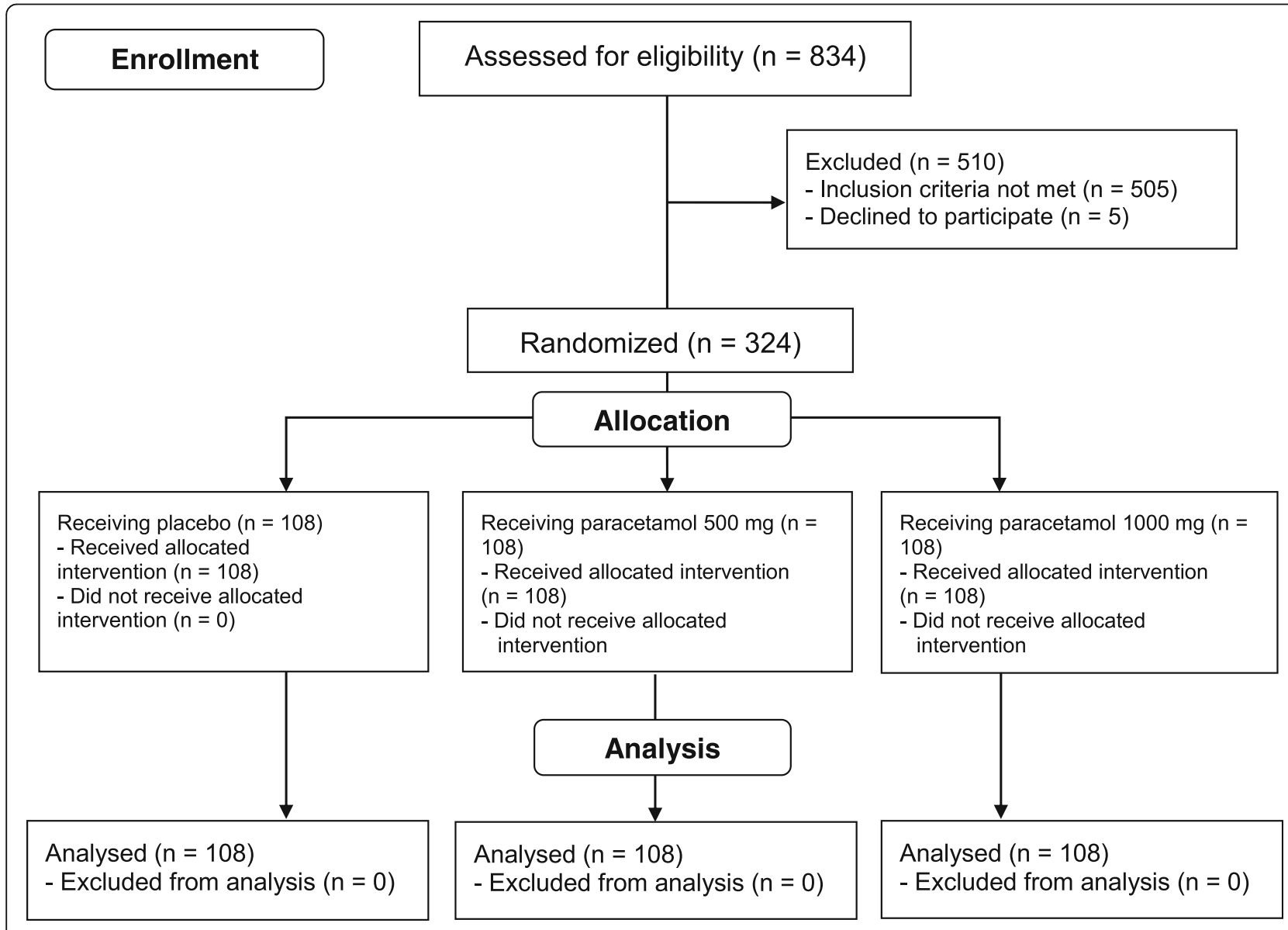

Fig. 1 Consort flow diagram of this study 
Table 1 Patient demographic data. All data are $\mathrm{n}(\%)$ or mean (SD)

\begin{tabular}{|c|c|c|c|c|}
\hline Patients & $\mathrm{Pb}(n=108)$ & P500 $(n=108)$ & P1000 $(n=108)$ & $P$-value \\
\hline \multicolumn{5}{|l|}{ Gender, n (\%) } \\
\hline - Male & $24(22.2)$ & $33(30.5)$ & $36(33.3)$ & 0.16 \\
\hline Age (yr), mean (SD) & $42.7(11.5)$ & $43(12.2)$ & $44.3(10.3)$ & 0.54 \\
\hline Weight (kg), mean (SD) & $62.5(9.6)$ & $62.8(9.8)$ & $62.8(9.1)$ & 0.96 \\
\hline Height (cm), mean (SD) & $159.5(7.4)$ & $160.3(7.3)$ & $159.5(8.2)$ & 0.67 \\
\hline BMI $\left(\mathrm{kg} / \mathrm{m}^{2}\right)$, mean (SD) & $24.6(3.6)$ & $24.4(3.4)$ & $24.8(3.5)$ & 0.80 \\
\hline ASA classification, n (\%) & & & & 0.19 \\
\hline-1 & 19 (17.6) & $28(25.9)$ & $23(21.3)$ & \\
\hline$-\|$ & $84(77.8)$ & $79(73.1)$ & $81(75)$ & \\
\hline$-\mid I I$ & $5(4.6)$ & $1(1)$ & $4(3.7)$ & \\
\hline $\mathrm{IPP}^{\mathrm{a}}$, mean (SD) & $65.1(32.1)$ & $66.5(28.3)$ & $70.8(28.9)$ & 0.35 \\
\hline
\end{tabular}

IIPP = interval between ingestion of paracetamol to injection of propofol (minutes)

Data are presented as the number of patients (\%) and mean \pm SD values

Paracetamol is one of the most popular and frequently used pain killer throughout the world. The mechanisms of action are sophisticated and cover both peripheral and central antinocciceptive manners. The pain relief effect provided by paracetamol is via inhibition of the cyclooxygenase pathway centrally and peripherally, reducing the production of prostaglandins [18]. Nevertheless, its antiinflammatory effects are weak, probably due to poor effectiveness when the concentration of peroxidases is high at the area of inflammation [19]. Paracetamol has been postulated to be classified to the group of the so-called atypical NSAIDs, determined as peroxide sensitive analgesic and antipyretic drugs (PSAAD) [20]. It has been shown that paracetamol is a selective cyclooxygenase-2 inhibitor in vivo [21]. Other proposed possible modes of action are an endogenous cannabinoid

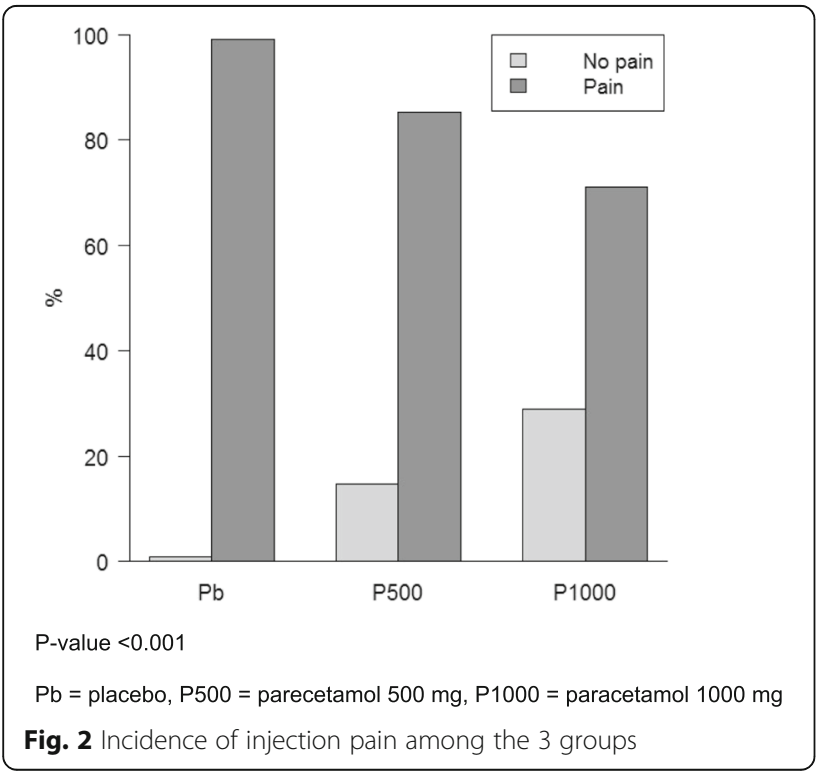

effect [22, 23], fatty acid amide hydrolase (FAAH)-dependent metabolism of acetaminophen into $\mathrm{N}$-arachidonoylphenolamine (AM404) [23], and a modulatory effect on the descending serotoninergic bulbospinal inhibitory pathway $[24,25]$ as concurrent administration of granisetron or tropisetron with paracetamol completely blocks the analgesic effect of paracetamol [26]. Pain relieving effect of paracetamol might also be a result of inhibition of nitric oxide (NO) formation. The synthesis of $\mathrm{NO}$ is through activation of L-arginine/NO pathway by substance P (SP) and N-methyl-D-aspartate (NMDA) receptors. NO is an important neurotransmitter involved in nociceptive process of the spinal cord $[27,28]$. Ohashi $\mathrm{N}$, et al. suggest that paracetamol metabolite $\mathrm{N}$-acylphenolamine induces analgesic effect directly via transient receptor potential vanilloid 1 (TRPV1) receptors expressed on central terminals of $\mathrm{C}$-fibers in the spinal dorsal horn and leads to conduction block, shunt currents, and desensitization of these fibers [29]. Treatment with paracetamol within $24 \mathrm{~h}$ of intensive care unit admission may lessen oxidative injury and improve renal function in adult patients with severe sepsis and detectable plasma cell-free hemoglobin [30].

Table 2 Number of patients experiencing propofol injection pain among the 3 groups

\begin{tabular}{llll}
\hline $\begin{array}{l}\text { Severity of pain } \\
\mathrm{n}(\%)\end{array}$ & $\begin{array}{l}\text { Pb group } \\
(n=108)\end{array}$ & $\begin{array}{l}P \text { 500 group } \\
(n=108)\end{array}$ & $\begin{array}{l}P \text { 1000 group } \\
(n=108)\end{array}$ \\
\hline None (VNRS 0) & $1(0.9)$ & $15(13.9)$ & $32(29.6)$ \\
Mild (VNRS 1-2) & $0(0)$ & $31(28.7)$ & $51(47.2)$ \\
Moderate (VNRS 4-6) & $24(22.2)$ & $54(50)$ & $25(23.2)$ \\
Severe (VNRS 7-10) & $83(76.9)$ & $8(7.4)$ & $0(0)$ \\
\hline
\end{tabular}

$P$-value $<0.001$ among the 3 groups and $P$-value $<0.001$ for $\mathrm{Pb}$ vs $\mathrm{P} 500, P$ value $<0.001$ for $\mathrm{Pb}$ vs $\mathrm{P} 1000, P$-value $<0.001$ for $\mathrm{P} 500$ vs $\mathrm{P} 1000$ $\mathrm{Pb}$ placebo, $P 500$ parecetamol $500 \mathrm{mg}, P 1000$ paracetamol $1000 \mathrm{mg}$ VNRS verbal numerical rating score

Data are presented as the number of patients (\%) 


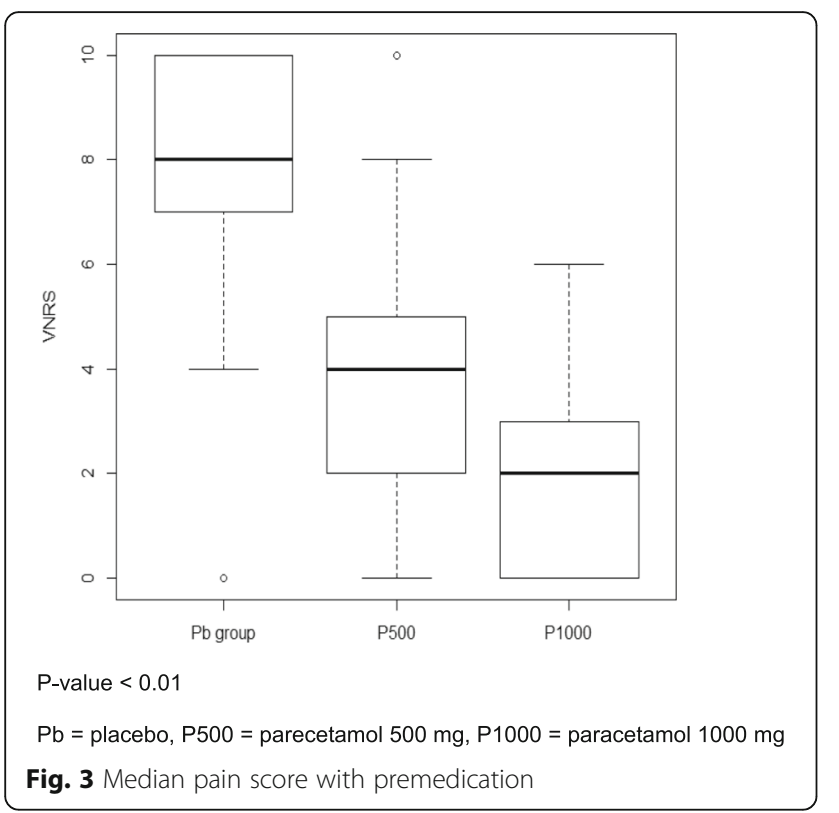

Paracetamol has been found as effective for reducing propofol injection pain. Canbay et al. [15] conducted a double-blinded RCT in 150 patients and showed that the incidence of propofol injection pain was $64 \%$ in the control group and $22 \%$ in the intravenous paracetamol pretreatment group. Khouadja et al. [31] performed a double-blinded RCT in 180 patients and also showed similar results, $85 \%$ in the control group and $36.6 \%$ in the intravenous paracetamol group. Our results revealed that premedication with oral paracetamol reduced the incidence and severity of propofol injection pain. It added more information that oral paracetamol was also effective for this type of pain.

In our study, the overall incidence of pain during propofol injection was higher than other studies. The previous 3 studies $[15,31,32]$ used intravenous paracetamol, not oral tablet as we did. Oral form of paracetamol exerts different pharmacokinetics and pharmacodynamics in comparison to intravenous form. This is why our results (using oral paracetamol) somewhat differed from other previous studies (using intravenous paracetamol) in terms of incidence and severity of propofol injection pain. Singla et al. [33] has shown that intravenous paracetamol has earlier and higher plasma level compared with oral paracetamol. After administration, plasma concentration of intravenous paracetamol reaches its peak rapidly within $15 \mathrm{~min}$ as shown by a very steep part of its graph. Plasma concentration of oral paracetamol at any time of measurement $(0.25,0.5,0.75,1,2,3,4$ and $6 \mathrm{~h})$ is much lower than that of intravenous paracetamol at $15 \mathrm{~min}$. The intravenous route provides a $76 \%$ higher maximum concentration $\left(C_{\max }\right)$ than the oral route.
The other reasons that the incidence of propofol injection pain in the paracetamol group in previous studies was lower than ours may be from inserting a bigger venous catheter [31] and/or using a venous occlusion technique $[15,31]$. It has been demonstrated that this tourniquet technique can help to increase the effectiveness of intravenous paracetamol in reducing propofol injection pain [32]. Canbay et al. [15] occluded their patient's vein and gave pretreatment of intravenous paracetamol over $10 \mathrm{~s}$. The patient's vein was further occluded for 2 more minutes before releasing. Propofol was given after the patient's vein had been released. Pain was measured during $5 \mathrm{~s}$ of paracetamol injection. The patients in Canbay et al.'s study rated their pain within the period of the highest plasma concentration of paracetamol. Regarding analgesic effects provided by intravenous in comparison with oral paracetamol, Fenlon S. et al. performed a study in 128 patients scheduled for lower third molar extraction. It has been shown that oral paracetamol is not inferior than intravenous paracetamol for providing postoperative analgesia in patients undergoing dental surgery [34].

According to the severity of pain, the incidence of mild, moderate, and severe pain was also significantly different in our P1000, P500 and Pb groups. These findings indicate that premedication with oral paracetamol reduce propofol injection pain by means of a dosedependent fashion.

Different method of assessing pain severity may also explain our different results on severity of propofol injection pain. We used a Verbal Numerical Rating Score (VNRS) ranging from 0 to 10 (11 points) to measure our patients' pain. All of our patients verbally reported their pain by themselves ('subjective' assessment). The other studies used a 4 -point scale $(0=$ none, $1=$ mild, $2=$ moderate and $3=$ severe). They did not mainly ask their patients to verbally rate the level of pain upon propofol injection but they principally observed their patients' pain behaviors ('observational' assessment): $0=$ none (negative response to questioning), $1=$ mild pain (pain reported only in response to questioning with no behavioral signs), 2 = moderate pain (pain reported in response to questioning and accompanied by a behavioral sign or pain reported spontaneously without questioning), and $3=$ severe pain (strong vocal response or response accompanied by facial grimacing, arm withdrawals or tears). Measuring pain by the VNRS is reliable, valid, sensitive to change, and easy to administer [35]. We did not use behavioral assessment because it is not subjective and less reliable.

This study found no adverse consequence of paracetamol.

Strengths of this study are utilization of a simple analgesic (paracetamol) and administered it to the patients 
in a simple way (oral route). Considering that oral paracetamol has been shown to increase the incidence of no pain as well as to reduce the incidence of severe pain upon propofol injection, the results of this study are clinically useful and applicable to daily practice because oral paracetamol is readily and widely available, practically simple and convenient to use as well as economic wise. As our study's protocol is easy to apply and early administration or oral paracetamol is pharmacologically sensible, the result of this study can be clinically applied in general.

Limitations of this study are a subjective method of pain intensity measurement and the fractional dose of given propofol. The intensity of propofol injection pain was rated by using the verbal numerical rating score (VNRS), although patient's self-assessment is the gold standard of pain intensity measurement but it is subjective and depends of each individual. Because propofol is a powerful induction agent, we could not inject the entire dose of propofol to each patient before measuring the pain intensity as a significant number of them felt asleep and were unable to give the pain rating.

\section{Conclusions}

Premedication with oral paracetamol can reduce propofol injection pain on a dose-dependent basis, without causing any adverse effect. As propofol injection pain is common and remains a concern of anesthesia providers for the comfort of their patients, and early oral administration of paracetamol is pharmacologically sensible, easy to apply, well-tolerated, available and economic, the results of this study provide the basis for changing practice with a positive impact on patient care.

\section{Abbreviations}

ALT: Alanine transminase; ASA: American Society of Anesthesiologists; AST: Aspartate transaminase; BMI: Body mass index; $C_{\text {max }}$ : Maximum concentration; COX: Cyclooxygenase; IQR: Interquartile range; NMDA: Nmethyl-D-aspartate; NO: Nitric oxide; NSAIDs: Non-steroidal anti-inflammatory drugs; PSAAD: Peroxide sensitive analgesic and antipyretic drugs;

SD: Standard deviation; SP: Substance P; VNRS: Verbal numerical rating score

\section{Acknowledgements}

Department of Anesthesiology, Faculty of Medicine, Prince of Songkla University.

\section{Funding}

This study was funded by the Faculty of Medicine, Prince of Songkla University. It had no external funding.

\section{Availability of data and materials}

The datasets generated and/or analyzed during the current study will be available from the corresponding author on reasonable request.

\section{Authors' contributions}

SN and MJ participated in protocol writing, collecting data, statistical analysis, interpretation of results and manuscript writing. SP participated in protocol writing, interpretation of results and manuscript writing. MO did the statistical analysis and reviewed the manuscript. All authors read and approved the final manuscript.

\section{Ethics approval and consent to participate}

This study was approved by the Faculty of Medicine, Prince of Songkla University Ethics Committee with the reference number 57-358-08-1. It was also registered with Thai Clinical Trial Registry with the reference number TCTR20150224002.

All participants were informed and asked for written informed consent.

Consent for publication

Not applicable.

\section{Competing interests}

The authors declare that they have no competing interests.

\section{Publisher's Note}

Springer Nature remains neutral with regard to jurisdictional claims in published maps and institutional affiliations.

Received: 5 February 2019 Accepted: 14 May 2019

Published online: 11 June 2019

\section{References}

1. Tan CH, Onsiong MK. Pain on injection of propofol. Anaesthesia. 1998; 53:468-76.

2. Stark RD, Binks SM, Dutka VN, O'Connor KM, Arnstein MJA, Glen JB. A review of the safety and tolerance of propofol (Diprivan). Postgrad Med J. 1985;61:152-6.

3. Manger $\mathrm{D}$, Holak EJ. Tourniquet at $50 \mathrm{mmHg}$ followed by intravenous lidocaine diminishes hand pain associated with propofol injection. Anesth Analg. 1992;74:250-2.

4. Klement W, Arndt JO. Pain on intravenous injection of some anaesthetic agents is evoked by the unphysiological osmolarity or $\mathrm{pH}$ of their formulations. Br J Anaesth. 1991;66:189-95.

5. Nakane M, Iwama H. A potential mechanism of propofol-induced pain on injection based on studies using nafamostat mesilate. $\mathrm{Br} J$ Anaesth. 1999:83:397-404.

6. McCulloch MJ, Lees NW. Assessment and modification of pain on induction with propofol (Diprivan). Anaesthesia. 1985;40:1117-20.

7. Scott RPF, Saunders DA, Norman J. Propofol: clinical strategies for preventing pain on injection. Anaesthesia. 1988:43:492-4.

8. Briggs LP, Clarke RSJ, Dundee JW, Moore J, Bahar M, Wright PJ. Use of di-isopropyl phenol as main agent for short procedures. Br J Anaesth. 1981:53:1197-201.

9. Huang CL, Wang YP, Cheng YJ, Susetio L, Liu CC. The effect of carrier intravenous fluid speed on the injection pain of propofol. Anesth Analg. 1995;81:1087.

10. McDonald DS, Jameson P. Injection pain with propofol. Reduction with aspiration of blood. Anaesthesia. 1996;51:878-80.

11. Ganta R, Fee JP. Pain on injection of propofol: comparison of lignocaine with metoclopramide. Br J Anaesth. 1992;69:316-7.

12. Kizilcik N, Menda F, Bilgen S, Keskin O, Koner O. Effects of a fentanylpropofol mixture on propofol injection pain: a randomized clinical trial. Korean J Anesthesiol. 2015;68:556-60.

13. Bahar M, McAteer E, Dundee JW, Briggs LP. Aspirin in the prevention of painful intravenous injection of disoprofol $(\mathrm{ICl} 35,868)$ and diazepam (valium). Anaesthesia. 1982;37:847-8.

14. Jalota L, Kalira V, George E, Shi YY, Hornuss C, Radke O, et al. Prevention of pain on injection of propofol: systematic review and meta-analysis. Cited as. BMJ. 2011;342:d1110.

15. Canbay O, Celebi N, Arun O, Karagoz H, Sarıcaoglu F, Ozgen S. Efficacy of intravenous acetaminophen and lidocaine on propofol injection pain. $\mathrm{Br} J$ Anaesth. 2008;100:95-8.

16. Borazan H, Erdem TB, Kececioglu M, Otelcioglu S. Prevention of pain on injection of propofol: a comparison of lidocaine with different doses of paracetamol. Eur J Anaesthesiol. 2010;27:253-7.

17. Seymour RA, Kelly PJ, Hawkesford JE. The efficacy of ketoprofen and paracetamol (acetaminophen) in postoperative pain after third molar surgery. Br J Clin Pharmacol. 1996;41:581-5.

18. Jozwiak-Bebenista M, Nowak JZ. Paracetamol: mechanism of action, applications, and safety concern. Acta Pol Pharm. 2014;71:11-23. 
19. Candido KD, Perozo OJ, Knezevic NN. Pharmacology of acetaminophen, nonsteroidal antiinflammatory drugs, and steroid medications: implications for anesthesia or unique associated risks. Anesthesiol Clin. 2017;35:e145-62.

20. Graham GG, Scott KF. Mechanisms of action of paracetamol and related analgesics. Inflammopharmacology. 2003;11:401-13.

21. Lee YS, Kim H, Brahim JS, Rowan J, Lee G, Dionne RA. Acetaminophen selectively suppresses peripheral prostaglandin $E_{2}$ release and increases COX-2 gene expression in a clinical model of acute inflammation. Pain. 2007;129:279-86.

22. Mallet $C$, Barriera DA, Ermund A, Jonsson BAG, Eschalier A, Zygmunt PM, et al. TRPV1 in brain is involved in acetaminophen-induced antinociception. PLoS One. 2010;5:e12748.

23. Mallet C, Daulhac L, Bonnefont J, Ledent C, Etienne M, Chapuy E, et al. Endocannabinoid and serotonergic systems are needed for acetaminopheninduced analgesia. Pain. 2008:139:190-200.

24. Pickering G, Esteve V, Loriot MA, Eschalier A, Dubray C. Acetaminophen reinforces descending inhibitory pain pathways. Clin Pharmacol Ther. 2008;84:47-51.

25. Bonnefont J, Alloui A, Chapuy E, Clottes E, Eschalier A. Orally administered paracetamol does not act locally in the rat formalin test: evidence for a supraspinal, serotonin-dependent antinociceptive mechanism. Anesthesiology. 2003;99:976-81.

26. Pickering G, Loriot MA, Libert F, Eschalier A, Beaune P, Dubray C. Analgesic effect of acetaminophen in humans: first evidence of a central serotonergic mechanism. Clin Pharmacol Ther. 2006;79:371-8.

27. Bjorkman R. Central antinociceptive effects of non-steroidal antiinflammatory drugs and paracetamol. Experimental studies in the rat. Acta Anaesthesiol Scand. 1995;103(Suppl.):1-44.

28. Bujalska M. Effect of nitric oxide synthase inhibitor on antinociceptive action of different doses of acetaminophen. Pol J Pharmacol. 2004;56:605-10.

29. Ohashi N, Uta D, Sasaki M, Ohashi M, Kamiya Y, Kohno T. Acetaminophen metabolite $\mathrm{N}$-acylphenolamine induces analgesia via transient receptor potential vanilloid 1 receptors expressed on the primary afferent terminals of C-fibers in the spinal dorsal horn. Anesthesiology. 2017;127:355-71.

30. Janz DR, Bastarache JA, Rice TW, Bernard GR, Warren MA, Wickersham $\mathrm{N}$, et al. Randomized, placebo-controlled trial of acetaminophen for the reduction of oxidative injury in severe sepsis: the acetaminophen for the reduction of oxidative injury in severe Sepsis trial. Crit Care Med. 2015:43:534-41.

31. Khouadja H, Arnous H, Tarmiz K, Beletaifa D, Brahim A, Brahem W, et al. Pain on injection of propofol: efficacy of paracetamol and lidocaine. Open J Anesthesiol. 2014;4:81-7.

32. Ozkan S, Sen H, Sizlan A, Yanarates O, Mutlu M, Dagli G. Comparison of acetaminophen (with or without tourniquet) and lidocaine in propofol injection pain. Klinik Psikofarmakol Bülteni. 2011;21:100-4.

33. Singla NK, Parulan C, Samson R, Hutchinson J, Bushnell R, Beja EG, et al. Plasma and cerebrospinal fluid pharmacokinetic parameters after single dose administration of intravenous, oral or rectal acetaminophen. Pain Pract. 2012;12:523-32.

34. Fenlon S, Collyer J, Giles J, Bidd H, Lees M, Nicholson J, et al. Oral vs intravenous paracetamol for lower third molar extractions under genera anaesthesia: is oral administration inferior? Br J Anaesth. 2013;110:432-7.

35. Bendinger T, Plunkett N. Measurement in pain medicine. BJA Education. 2016;16:310-5

\section{Ready to submit your research? Choose BMC and benefit from:}

- fast, convenient online submission

- thorough peer review by experienced researchers in your field

- rapid publication on acceptance

- support for research data, including large and complex data types

- gold Open Access which fosters wider collaboration and increased citations

- maximum visibility for your research: over $100 \mathrm{M}$ website views per year

At $\mathrm{BMC}$, research is always in progress.

Learn more biomedcentral.com/submissions 